\section{OPEN ACCESS}

Edited by:

Giuseppina Rea,

National Research Council of Italy, Italy

Reviewed by:

Renato Grillo,

Federal University of $A B C$, Brazil

Fabio Polticelli,

Roma Tre University, Italy

*Correspondence:

Chibuike C. Udenigwe

cudenigwe@dal.ca

Specialty section:

This article was submitted to

Agricultural Biological Chemistry,

a section of the journal

Frontiers in Chemistry

Received: 28 April 2016

Accepted: 05 July 2016

Published: 20 July 2016

Citation:

Rajendran SRCK, Udenigwe CC and Yada RY (2016) Nanochemistry of

Protein-Based Delivery Agents.

Front. Chem. 4:31.

doi: 10.3389/fchem.2016.00031

\title{
Nanochemistry of Protein-Based Delivery Agents
}

\author{
Subin R. C. K. Rajendran ${ }^{1}$, Chibuike C. Udenigwe ${ }^{1 *}$ and Rickey Y. Yada ${ }^{2}$ \\ ${ }^{1}$ Department of Environmental Sciences, Dalhousie University, Truro, NS, Canada, ${ }^{2}$ Faculty of Land and Food Systems, \\ University of British Columbia, Vancouver, BC, Canada
}

The past decade has seen an increased interest in the conversion of food proteins into functional biomaterials, including their use for loading and delivery of physiologically active compounds such as nutraceuticals and pharmaceuticals. Proteins possess a competitive advantage over other platforms for the development of nanodelivery systems since they are biocompatible, amphipathic, and widely available. Proteins also have unique molecular structures and diverse functional groups that can be selectively modified to alter encapsulation and release properties. A number of physical and chemical methods have been used for preparing protein nanoformulations, each based on different underlying protein chemistry. This review focuses on the chemistry of the reorganization and/or modification of proteins into functional nanostructures for delivery, from the perspective of their preparation, functionality, stability and physiological behavior.

Keywords: protein nanoparticles, bioavailability, nanochemistry, protein chemistry, nanodelivery systems

\section{INTRODUCTION}

The physical and chemical properties of proteins can be modified for specific food and biotechnological applications. Synthesis of protein-based nanodelivery vehicles can result in chemical and conformational changes that alter the protein functionality. Proteins have specific structures and a number of functional groups that are responsible for the physiochemical properties that can be selectively modified during the preparation of nanostructures. It is crucial to understand the underlying changes in the molecular conformation and chemical modifications induced during the production phase so as to design specific applications for these nanodelivery systems. Interfacial affinity is responsible for the adsorption of proteins as stabilizers or shells of emulsions or other materials thereby forming nanodelivery systems. In addition, the interfacial affinity of proteins for oil/water interface is greater than that of air/water interface (Santiago et al., 2008). Once the proteins are adsorbed, steric and electrostatic interactions can stabilize the particulate suspensions (Dalgleish, 2006). This review presents the different techniques employed for the production of protein nanodelivery systems from the perspective of the mechanisms involved in their formation while focusing on the conformational and chemical changes in proteins with respect to delivery applications, nanoparticle preparation, stability and cellular uptake.

\section{PRODUCTION OF PROTEIN NANODELIVERY SYSTEMS}

\section{Coacervation}

The electrostatic attractions between various components of the nanocomplexes drive the formation of coacervated nanocomplexes. However, the protein net charge is zero at the $\mathrm{pI}$, leading to $\mathrm{pH}$-related instability issues for protein nanoparticles. Thus, $\mathrm{pH}$ plays a major role 
in complex formation via its role in determining the degree of ionization of proteins (Priftis et al., 2012). Crosslinking is one of the approaches that can be used to overcome this issue. However, Zeeb et al. (2013) demonstrated that laccase-induced crosslinking of whey protein isolate (WPI)-pectin coacervate did not improve the $\mathrm{pH}$ stability of the nanoparticles. Heat treatment on the other hand had better impact on the nanoparticle stability (Zeeb et al., 2013). Moreover, formation of stable WPI complexed nanoparticles has been achieved by heat induced gelation following coacervation (Dai et al., 2015). Furthermore, anionically supercharged model proteins has been used to demonstrate that higher protein charge can increase the stability of protein micelles, which were found to be resistant to heat and dehydration (Obermeyer et al., 2016). The $\mathrm{pH}$-induced instability of coacervate nanocomplexes has promise for pharmaceuticals with relevance in the design of stimuli-responsive drug release particles. Even though electrostatic interactions have been implicated in coacervates associations, a contrasting mechanism has been recently reported suggesting that the enthalpy and entropic forces drive the free energy for polyion association in aqueous solutions that leads to complexation ( $\mathrm{Fu}$ and Schlenoff, 2016). In terms of changes to secondary structure as a result of processing, it is worth mentioning that no significant complexation-induced conformational changes were observed in nanoparticles prepared from pea protein isolate and alginate (Klemmer et al., 2012).

\section{Heat-Induced Gelation}

Cold gelation of proteins is a two-step process involving: (1) preparation of aggregate by heat treatment, and (2) induction of gelation at ambient temperature by gradually lowering the $\mathrm{pH}$ (i.e., $\mathrm{pH}$-induced gelation) or by the addition of salt (i.e., ionic gelation). Some of the inter- and intramolecular interactions that contribute to the process of protein gelation are ionic bonds, hydrogen bonds, hydrophobic interactions, and disulfide bonds (Sun and Arntfield, 2012). The addition of calcium or lowering the $\mathrm{pH}$ in the second step of the process neutralizes the structural unit surface charges leading to the formation of a three-dimensional network stabilized by some of the forces mentioned above (Maltais et al., 2008). Coacervation followed by heat-induced gelation of Maillard conjugates of WPI and dextran was found to form stable $(\mathrm{pH}$ $1-8,200 \mathrm{mM} \mathrm{NaCl}$ ) nanoparticles stabilized by steric repulsive and electrostatic interactions (Dai et al., 2015). Increase in temperature, protein concentration and decrease in $\mathrm{pH}$ were found to increase the size of ovalbumin-based nanoparticles (Sponton et al., 2015). In contrast, it was reported that thermal treatment did not improve the physical stability properties of soy protein isolate-stabilized emulsions (Fernández-Ávila et al., 2015). Moreover, heat denatured $\beta$-lactoglobulin has been used to coat and stabilize nanosuspensions $(\sim 200 \mathrm{~nm})$ of paclitaxel (Li et al., 2015). Hydrophobic interactions between the protein and drug in the nanoparticle suspension resulted in the loss of both tertiary and secondary protein structures, particularly a decrease in the $\alpha$-helix content (Li et al., 2015). Binding ability of proteins to polyunsaturated fatty acids (PUFA) to form nanocomplexes was also shown to depend on the surface area, hydrophobicity and spatial conformation of hydrophobic surface of the proteins (Perez et al., 2014; Sponton et al., 2015). Ohmic heating is a relatively new technique used to tailor the denaturation and aggregation behavior of proteins with the help of uniform electric fields to develop novel nano-hydrogels (Pereira et al., 2015; Rodrigues et al., 2015). This technique can introduce uniform heating facilitating the modulation of desired properties across the suspension. In general, decrease in protein structure (i.e., structured $\alpha$-helix content) has been associated with heat-induced gelation. For instance, decrease in $\alpha$-helix structure and increase in $\beta$-sheet/turns was reported for cruciferin nanoparticles formed via calcium-induced gelation (Figure 1; Akbari and $\mathrm{Wu}, 2016)$. Similarly, formation of calcium-induced soy protein nanoparticles also significantly increased the antiparallel $\beta$-sheet content (Zhang et al., 2012). These findings suggest a nanoparticle formation mechanism involving antiparallel $\beta$-sheets, as discussed later in this review.

\section{Antisolvent Precipitation}

Antisolvent precipitation involves the precipitation of protein aggregates by the addition of a non-solvent (antisolvent) to the protein solution, as shown in Figure 2. The major issue with solution precipitation is the solvent recovery for reuse. Supercritical fluids have been widely employed in the preparation of powder formulations of bioactive compounds because of their low cost, mild process conditions and non-flammable and nontoxic properties. Dense gas-based techniques of precipitation have been demonstrated to be suitable for the production of sub-micro biologically active protein particles with model proteins (Thiering et al., 2000). There is a consensus that the generation of uniformly sized protein micro/nanospheres can significantly promote the predictability of physiological absorption. This is evident from a study that demonstrated that salmon calcitonin prepared by supercritical fluid-assisted spraydrying has a higher absorption and bioavailability compared to spray dried and raw calcitonin (Cho et al., 2015). $\mathrm{CO}_{2}$-based supercritical antisolvent precipitation has also been used to prepare lysozyme nanoparticles that retained $87 \%$ of its native activity (Chattopadhyay and Gupta, 2002). Preparation of bovine serum albumin microparticles by supercritical fluidassisted atomization, introduced by a hydrodynamic cavitation mixer (SAA-HCM), resulted in a decrease in the protein $\alpha$ helix from $63 \%$ in the native protein to $55 \%$ after SAA-HCM (Wang et al., 2011). In the study, $\beta$-sheet content was found to increase by $17 \%$ with most of the secondary structure intact (Wang et al., 2011); mechanism for $\beta$-sheet increase is presented in Figure 1. Therefore, from the report on enzyme activity and conformational studies, antisolvent precipitation can be considered a relatively less destructive method. Crystallization/precipitation and evaporative precipitation are some of the other similar methods in nanoparticle synthesis that can induce protein precipitation via solvent unavailability.

\section{Enzymatic and Chemical Crosslinking}

Chemical crosslinking is often employed to chemically harden synthesized nanoparticles by inducing inter- and intra-molecular covalent linkages. Gliadin-based nanoparticles prepared by 

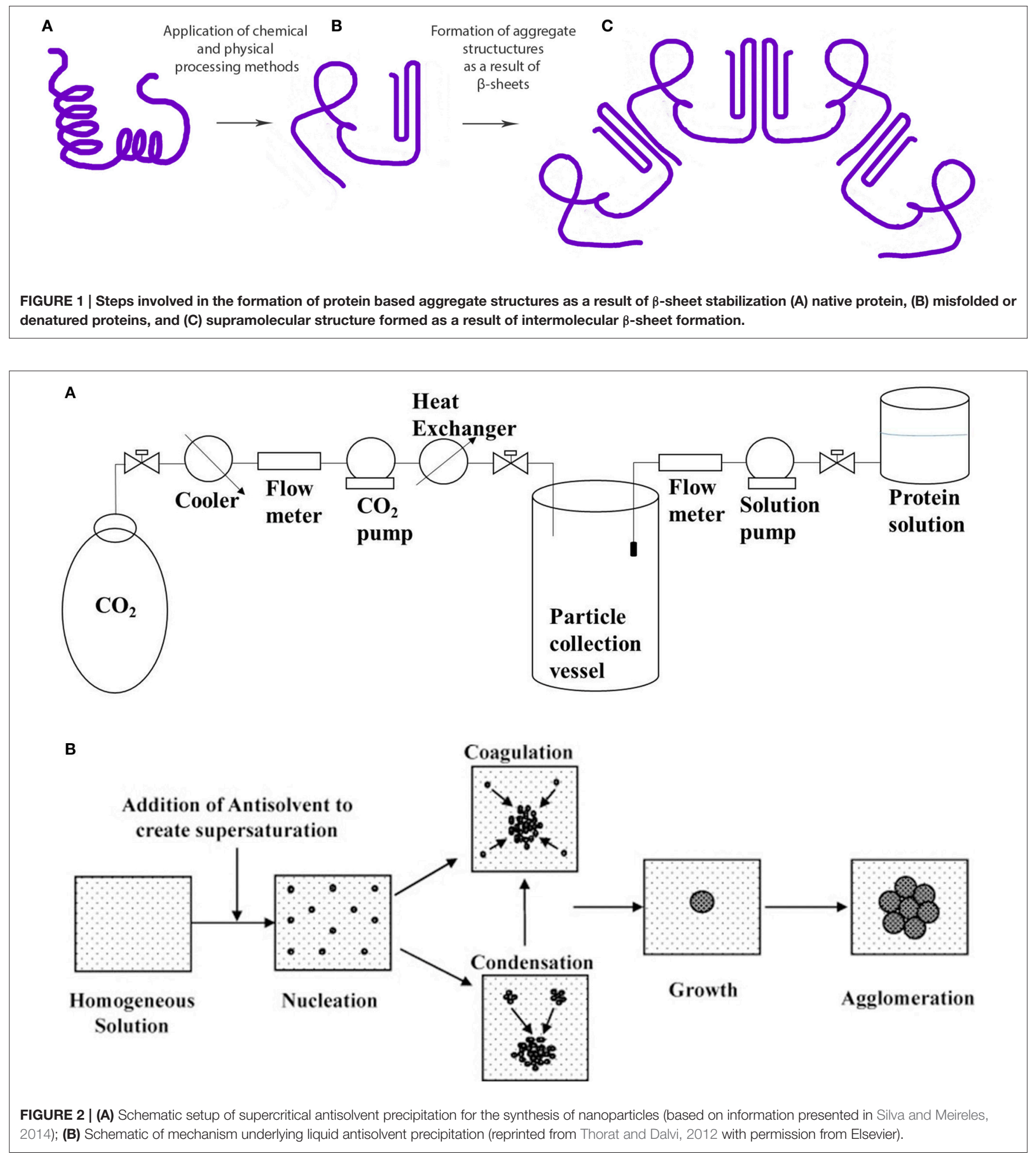

antisolvent precipitation was found to be hardened by chemical crosslinking with glutaraldehyde, and this was demonstrated to have only a slight improvement on the stability (Joye et al., 2015). Similarly, $\beta$-lactoglobulin nanoparticles have also been chemically hardened (Teng et al., 2013, 2016). Addition of crosslinking agents has been shown to have no substantial impact on mean particle size, and it slightly decreased the zeta potential of the particles (Weber et al., 2000). To overcome the negative effects of chemical agents, such as toxicity or undesirable reactions, a recent study reported the use of ionizing radiation to 
prepare albumin nanoparticles by induced cross-linking (Achilli et al., 2015). However, in the study, there was a $20 \%$ loss in the $\alpha$-helix content of albumin as a result of ionizing radiation treatment.

Enzymatic crosslinking has been successfully used for the preparation of protein nanoparticles of particular size and structure using transglutaminase, peroxidase, tyrosinase and laccase. Transglutaminase has been demonstrated to induce protein glycation and crosslinking, thereby improving the protein interfacial properties (Jiang and Zhao, 2010). The crosslinking process has resulted in a reduction of thickness in the adsorbed protein layer (Partanen et al., 2013), along with a decrease in ordered secondary structures (Ercili-Cura et al., 2012). However, excess crosslinking between lysine and glutamine residues can result in a decrease in protein digestibility. To address the latter, soy protein isolate deamidation has been found to decrease glycation and crosslinking induced by transglutaminase, giving the products higher digestibility, less increased hydration, lower thermal stability, and relatively unfolded secondary structure, and this can, therefore, be used as a means to control the degree of crosslinking or transglutaminase activity (Yao and Zhao, 2016).

\section{Ultrasonication}

Ultrasonic treatment of liquids creates acoustic cavitation, which is the formation, growth and collapse of bubbles that induce localized production of heat and can drive chemical reactions. Specifically, sonolysis of water forms free radicals, $\bullet \mathrm{OH}$ and $\mathrm{H} \bullet$, which can lead to the generation of superoxide anion radicals and $\mathrm{H}_{2} \mathrm{O}_{2}$, which in turn can act as protein crosslinking agents (Weissler, 1959). This process involves the lowering of the free protein cysteine thiol groups thereby inducing disulfide linkages. However, proteinaceous microspheres have been prepared using non-S containing streptavidin indicating that other factors also play a role in the formation of macromolecular structures besides disulfide linkages when using ultrasonication (Avivi and Gedanken, 2002). It has been demonstrated that oil-in-water emulsions prepared by sonication treatment have $\mathrm{OH}^{-}$adsorbed on the outer surface that stabilizes these emulsions (Reddy and Fogler, 1980; Kamogawa et al., 2004). Whether a similar mechanism exists for protein-stabilized emulsions has yet to be elucidated. Ultrasonication can breakdown whey proteins aggregates formed during pre-heat treatment and also prevent their reformation (Ashokkumar et al., 2009). Moreover, the surface hydrophobicity of whey proteins was found to initially increase on sonication as a result of protein unfolding, with a later decrease after $5 \mathrm{~min}$, presumably as a result of aggregation (Chandrapala et al., 2011). Moreover, sonication did not alter the thiol content in the study. In contrast, a study with soybean protein isolate reported an increase in thiol content following ultrasonication, and this was attributed to the exposure of $\mathrm{SH}$ groups in the unfolded protein (Hu et al., 2013). In contrast, ultrasound treatment of gelatin resulted in an increased solubility (Yu et al., 2016). Secondary structure modifications resulting from high-power ultrasonication of proteins differ from the effects of other treatments, with an increase in $\alpha$-helix content and a decrease in $\beta$-sheet (Hu et al., 2013). However, lower power ultrasonic treatment have been demonstrated to decrease the $\alpha$ helices and increase the $\beta$-sheets (Gülseren et al., 2007; Hu et al., 2013).

\section{High-Pressure Homogenization}

The process of high-pressure homogenization involves the passage of a mixture through a small orifice that result in turbulent flow conditions in combination with intense shear and cavitation (Figure 3), leading to the disruption of oil droplets/protein suspensions. High-pressure homogenization $(\mathrm{HPH})$ affected the supramolecular structure of soy proteins with significant increase in the denaturation temperature of treated samples (Keerati-U-Rai and Corredig, 2009). Moreover, the pressure-treated glycinin and soy protein isolate were observed to have larger soluble aggregate size, whereas $\beta$-conglycinin had a reduced aggregate amount following HPH (Keerati-U-Rai and Corredig, 2009). Dynamic high-pressure microfluidization has also been demonstrated to decrease $\alpha$-helix content and increase the $\beta$-sheets of zein-derived nanoparticles (Sun et al., 2015). HPH has been demonstrated to both improve and reduce the activity of enzymes depending on the type of enzyme, $\mathrm{pH}$, temperature and number of passes (Tribst et al., 2012, 2013). Therefore, HPH has potential applications in nanoencapsulation or nanoimmobilization of enzymes for improved recovery and activity.

\section{Electrospinning}

Electrospinning is a process that utilizes electrical forces to produce fibers with diameters ranging from $2 \mathrm{~nm}$ to several micrometers. For both electrospinning and electrospraying, a jet of liquid passes through a capillary tube, out a nozzle to a collector, and a voltage is applied between the tube and the collector. Based on the rheology of the solution emitted, the jet of liquid emitted from the nozzle either becomes dispersed as droplets or undergoes a whip-like motion to form fibers. Electrospun nanofibers have great promise in fabrication of nanostructured materials with enhanced properties. Gelatin and collagen nanofiber mats loaded with cefazolin and silver nanoparticles, respectively were demonstrated to be prospective technologies for improving wound healing (Rath et al., 2015, 2016). Nanofibers were cross-linked together using glutaraldehyde in these studies to form a mat-like structure. Moreover, zein nanofibers have been successfully fabricated for the sustained delivery of SiRNA into skin fibroblasts (Karthikeyan et al., 2015). The nature of the solvent determined the formation of either zein beads or fiber with ethonolic zein protein solutions resulting in fibers whereas isopropanolic solutions of zein generated beads (Moomand and Lim, 2014). In contrast, the extent of bead formation via has also been demonstrated to be controlled by the concentration of polymeric materials (Weiss et al., 2012), which in turn impacts the rheology of the solution. The extent of matrix swelling, erosion and diffusion was reported to determine the release kinetics of encapsulated fish oil from electrospun zein protein carriers (Moomand and Lim, 2014). Secondary structure modifications as a result of electrospinning can vary with protein concentration and solvent used, but a decrease in $\alpha$-helical structure was evident when compared to the native protein (Moomand and Lim, 2014). 


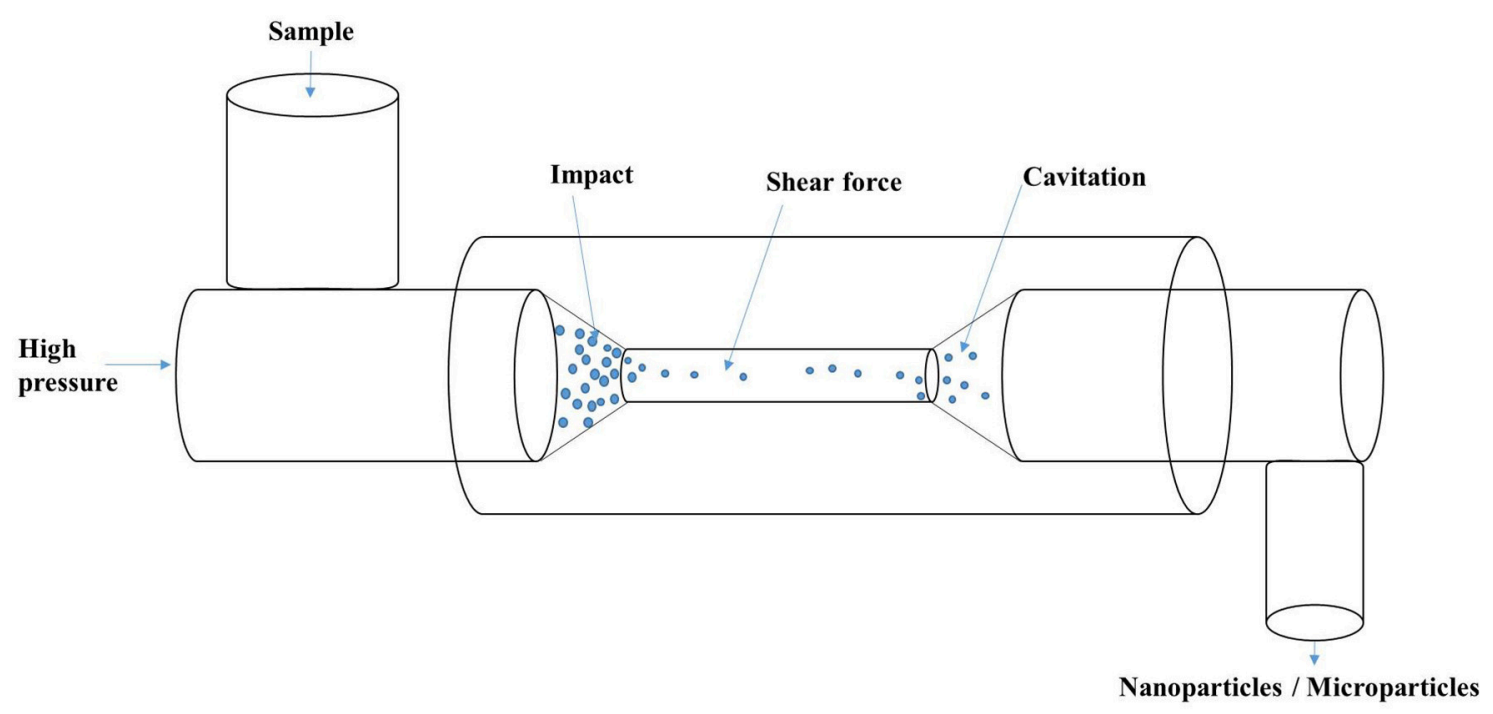

FIGURE 3 | Schematic of high-pressure homogenization showing the process of impact, shear and cavitation.

\section{Electrospraying}

Similar to electrospinning, electrospraying is an electric field induced atomization technique that forms charged selfdispersed droplets. Electrospraying has several advantages over conventional spray drying, including the production of (1) smaller sized and narrowly distributed particles, and (2) self-dispersing charged droplets with electric field governable motion (Jaworek, 2007). Reduction of protein concentration and flow rates have been demonstrated to decrease the particle size of electrosprayed protein particles (Gomez et al., 1998). Increased production of nanoparticles can be facilitated by increased flow rate, which has resulted in larger sizes of the particles (Gomez et al., 1998). Electrospraying appears to be a relatively nondestructive method, considering the insignificant differences observed in the activity of electrosprayed and untreated insulin (Gomez et al., 1998).

\section{Conjugation}

\section{For Targeted Delivery}

Conjugation of signaling peptides such as mitochondrial targeting signal peptides and cell-penetrating peptides has the potential to enable the targeting of nanoparticles to specific cells and cellular components. Folic acid tagged-protein nanoemulsions prepared by high-pressure homogenization was reported to promote specific folate receptor (FR)-mediated targeting $\mathrm{FR}^{+}$cells (Loureiro et al., 2015). However, the effectiveness of targeted delivery with respect to non-specific protein adsorption in vivo needs to be characterized for proteinbased nanomaterials. Some of the essential chemical strategies involving coupling, fusion and encapsulation of human serum albumin have been reviewed (Liu and Chen, 2016).

\section{For Enhanced Stability}

Proteins have almost zero charge near their pI, and this can disrupt the stabilizing effects of electrostatic interactions, and therefore, negatively affect protein stability over a range of $\mathrm{pH}$. Complexation and conjugation with a number of different materials enhances the surface chemistry of the nanoparticles for improved stability and physiological effects. Dextran is a neutral $\alpha-1^{\prime}$ glycosidic-linked glucose polysaccharide with high solubility, low viscosity, and low gelation properties. Dextran along with pectin and chitosan has been widely applied for glycosylation of proteins to avoid the complications from the formation of electrostatic complexes. Maillard reaction conjugates of sodium caseinate and dextran coated on zein nanoparticles encapsulating resveratrol was found to significantly improved the particle stability against changes in $\mathrm{pH}$ (2.0-9.0), $\mathrm{CaCl}_{2}$ addition $(100 \mathrm{mM})$ and heat treatment $\left(30-90^{\circ} \mathrm{C}, 30 \mathrm{~min}\right.$; Davidov-Pardo et al., 2015a). Similarly, algae oil nanoemulsions stabilized by a colloidal complex of zein hydrolysate and tannic acid, a polyphenol, demonstrated increased oxidative stability and emulsifying capacity compared to nanoemulsions stabilized by the hydrolysate alone (Wang et al., 2016).

\section{Modifications in the Secondary and Tertiary Structure of Proteins}

There is an increase in the $\beta$-sheet content in most of the chemical and physical methods employed for the synthesis of nanodelivery systems (Figure 1). These increases, in most cases, can be due to the formation of intermolecular $\beta$-sheets that stabilize protein aggregate units. Contrary to other processing methods and treatments, pulsed electric field treatments of soy protein isolate has resulted in decreased amount of $\beta$-turns, which were converted into ordered $\alpha$-helix structure, thereby increasing the content of the latter (Liu et al., 2011). Along with pulsed electric fields, high power ultrasonication treatment is the only exception among processing techniques that has resulted in an increase in the organized $\alpha$-helix structure ( $\mathrm{Hu}$ et al., 2013). Proteins with increased random coil structures 
have been shown to have better functional properties such as emulsification and thickening as their structure allows them to bind to larger amounts of water molecules or other chemical moieties (Davidov-Pardo et al., 2015b). In addition, as mentioned earlier, complex coacervate nanoparticles of pea protein isolate and alginate did not induce significant conformational changes compared to the control (Klemmer et al., 2012).

\section{Conformational Flexibility}

Low-level oxidation in protein isolates was demonstrated to improve flexible of the tertiary structure leading to the formation of soluble aggregates with enhanced emulsion stability; higher oxidation levels have resulted in the formation of insoluble aggregates (Chen et al., 2013; Ye et al., 2013). Most theoretical predictions suggest that the improved functional properties can be due to increased protein flexibility. For instance, as peptides have greater flexibility in their structures compared to intact proteins, Phoon et al. (2014) compared the emulsifying ability of intact $\beta$-conglycinin to its protein hydrolysates in $\mathrm{HPH}$ nanoemulsions of fish oil. Oxidative stability of the product was improved with the hydrolysate-coated emulsions compared to intact protein at $\mathrm{pH} \geq 7$. However, uneven interfacial coverage was observed on lowering the $\mathrm{pH}$ along with an increase in $\beta$-sheet formation, indicating aggregation (Phoon et al., 2014). Therefore, selection of encapsulating material for nanodelivery should consider additional physiochemical properties than just their improved emulsifying ability for the development of high quality delivery systems.

\section{Protein Interface and Interactions}

Numerous studies have elucidated the binding properties of bioactive compounds or drugs, and binding sites are known to increase in denatured conformation compared to the native state (Relkin et al., 2014). Understanding protein conformational changes during immobilization and adsorption can play a significant role in functional design of protein-based nanomaterials. As mentioned earlier, interfacial affinity can induce the adsorption of proteins (Santiago et al., 2008) and, depending on the properties of the encapsulating protein, it can stabilize emulsions via electrostatic and steric repulsions, with larger molecular weight proteins largely exhibiting both (Dalgleish, 2006). It has been demonstrated with silica nanoparticles that particle curvature plays a major role in perturbing protein secondary structure, i.e., larger diameters facilitate an increased particle-protein interaction surface thereby inducing more changes in the secondary structure (Lundqvist et al., 2004). Similarly, conformational changes at emulsion interfaces is determined by multiple factors such as inherent flexibility of the protein, the distribution of hydrophobic/hydrophilic domains within the protein sequence and the hydrophobicity of the oil phase (Zhai et al., 2013). The protein charge also plays a significant role in these interactions. Cationic $\beta$-lactoglobulin nanoparticles were found to have superior integrity compared to the native protein in simulated gastrointestinal conditions, displayed $770 \%$ higher mucoadhesion, greater transepithelial permeation, and elevated cellular uptake; the latter molecular structure displayed higher surface hydrophobicity and decrease in $\beta$ sheet conformation (Teng et al., 2013, 2016). The emulsifying properties of protein isolates are positively correlated with surface hydrophobicity, which have been found to increase upon multiple freeze-thaw cycles, and on ultrasonication (Zhang et al., 2014; Zhao et al., 2015). The relationship between $\beta$-sheet formation and the surface hydrophobicity of protein aggregate needs further studies in order to elucidate the mechanisms underlying protein nanoparticle formation.

\section{In Vivo Protein Adsorption: Relevance to Targeted Delivery}

Rational design of applicable nanomaterials requires the establishment of the principles underlying serum protein adsorption and cellular uptake (Walkey et al., 2012). There is a consensus that the outer surface of nanomaterials within biological systems is essentially covered by a protein corona as a result of non-specific adsorption and protein interactions. Furthermore, cellular and tissue responses of the nanomaterials depend on these corona compositions, which in turn have been demonstrated to be influenced by parameters such as size, shape, temperature, $\mathrm{pH}$, surface charge, surface functional groups, and hydrophilicity or hydrophobicity of the nanoparticles (Gossmann et al., 2015; Yallapu et al., 2015). Even protein corona repellant membrane-wrapped nanoparticles have resulted in a non-specific protein adsorption (corona formation). However, selective cellular uptake of these nanoparticles has been observed in antigen presenting cells (Xu et al., 2016). Furthermore, the adsorption and unfolding of a single bovine serum albumin protein was found to trigger nanoparticle aggregation (Dominguez-Medina et al., 2016). Therefore, protein adsorption and associated conformation changes can play a major role in determining nanoparticle stability.

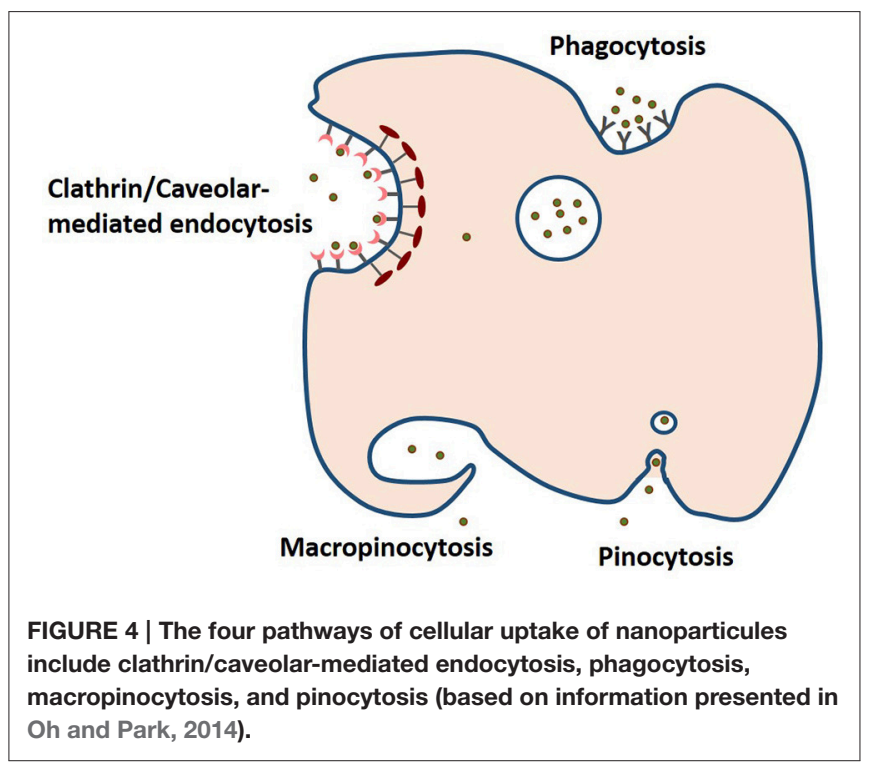




\section{Release and Cellular Uptake}

Release mechanism plays an important role in determining the efficacy of bioactive compound and drug nanodelivery. As mentioned earlier, matrix swelling, erosion and diffusion determine the release of the bioactive from the carrier. For instance, resveratrol-loaded zein nanoparticles prepared by antisolvent precipitation released the polyphenol independent of $\mathrm{pH}$, based on a combination of diffusion and erosion of the nanoparticle matrix leading to a 19.2-fold increase in the resveratrol oral bioavailability in a mouse model of endotoxic shock (Penalva et al., 2015). Hydrophobic bioactives are unavailable for absorption, but hydrated nanodelivery suspensions can enable them to be absorbed by a number of different mechanisms. Uptake and transport into cells depend on the stability, size, shape, $\zeta$-potential and release of the nanoparticles. As shown in Figure 4, phagocytosis, clathrin/caveolar-mediated endocytosis, micropinocytosis and pinocytosis are some of the mechanisms for cellular uptake of nanoparticles (Oh and Park, 2014). For instance, transferrin-coated Au particles $(<50 \mathrm{~nm})$ were reported to enter cells via clathrin-mediated endocytosis pathway. In contrast, $\beta$-lactoglobulin-stabilized paclitaxel nanosuspensions were demonstrated to directly translocate across the membrane into the cytosol in an energy-independent manner, i.e., via cholesterol-dependent membrane-fusion process (Li et al., 2015). Moreover, the shape of these nanomaterials can also influence this mode of cellular uptake. Cylindrical shaped nanoparticles are proposed to penetrate across the plasma membrane similar to a nanosyringe (Li et al., 2015). Surface-exposed functional groups can also determine the efficiency of cellular uptake of nanoparticles even under the influence of protein corona (Bai et al., 2015). Modification and masking of these surface functional groups will enable the tailoring of cellular uptake behavior of nanoparticles. To date, the major modes of cellular uptake of protein-encapsulated bioactive intended for food applications have yet to be determined.

\section{REFERENCES}

Achilli, E., Casajus, G., Siri, M., Flores, C., Kadłubowski, S., del Alonso, S. V., et al. (2015). Preparation of protein nanoparticle by dynamic aggregation and ionizing-induced crosslinking. Colloids Surf. A Physicochem. Eng. Asp. 486, 161-171. doi: 10.1016/j.colsurfa.2015.09.047

Akbari, A., and Wu, J. (2016). Cruciferin nanoparticles: preparation, characterization and their potential application in delivery of bioactive compounds. Food Hydrocoll. 54, 107-118. doi: 10.1016/j.foodhyd.2015.09.017

Ashokkumar, M., Lee, J., Zisu, B., Bhaskarcharya, R., Palmer, M., and Kentish, S. (2009). Hot topic: sonication increases the heat stability of whey proteins. J. Dairy Sci. 92, 5353-5356. doi: 10.3168/jds.2009-2561

Avivi, S., and Gedanken, A. (2002). S-S bonds are not required for the sonochemical formation of proteinaceous microspheres: the case of streptavidin. Biochem. J. 366, 705-707. doi: 10.1042/bj20020676

Bai, Y., Xing, H., Wu, P., Feng, X., Hwang, K., Lee, J. M., et al. (2015). Chemical control over cellular uptake of organic nanoparticles by fine tuning surface functional groups. ACS Nano 9, 10227-10236. doi: 10.1021/acsnano.5b03909

Chandrapala, J., Zisu, B., Palmer, M., Kentish, S., and Ashokkumar, M. (2011). Effects of ultrasound on the thermal and structural characteristics of proteins in reconstituted whey protein concentrate. Ultrason. Sonochem. 18, 951-957. doi: 10.1016/j.ultsonch.2010.12.016

\section{CONCLUSIONS AND FUTURE DIRECTION}

Interplay of the protein conformational flexibility, surface hydrophobicity, net charge and many inter- and intra-molecular interactions underlie the mechanisms of encapsulation with respect to nanodelivery. The potency of protein-based nanodelivery systems for targeted delivery of bioactive compounds is also highly dependent on the release mechanism and cellular uptake. There is still the need to elucidate the influence of preparation methods on the conformational state of proteins for nanodelivery. Several proteins from diverse sources have been used for the preparation of nanodelivery systems. However, there is a dearth of information on the physiochemical and biological properties of each of these proteins particularly related to their effectiveness as nanocarriers. Furthermore, the impact of carrier matrices such as oils (for delivery of hydrophobic bioactives) needs further consideration. In vivo protein corona can influence targeted delivery, but this has yet to be characterized for protein-based nanoparticles from the perspective of delivery efficiency. Filling some of these gaps is a major stride toward understanding and developing effective protein-based delivery systems for food applications.

\section{AUTHOR CONTRIBUTIONS}

SR, CU, and RY participated in the conception of the work. SR conducted the literature search and drafted the manuscript. CU and RY revised the scientific content of the manuscript.

\section{ACKNOWLEDGMENTS}

The research programs of $\mathrm{CU}$ and RY are supported by the Natural Sciences and Engineering Research Council of Canada (NSERC) Discovery Grants RGPIN 435865-2013 (CU) and RGPIN 2281-12 (RY).

Chattopadhyay, P., and Gupta, R. B. (2002). Protein nanoparticles formation by supercritical antisolvent with enhanced mass transfer. AIChE J. 48, 235-244. doi: 10.1002/aic.690480207

Chen, N., Zhao, M., Sun, W., Ren, J., and Cui, C. (2013). Effect of oxidation on the emulsifying properties of soy protein isolate. Food Res. Int. 52, 26-32. doi: 10.1016/j.foodres.2013.02.028

Cho, W., Kim, M.-S., Jung, M.-S., Park, J., Cha, K.-H., Kim, J.-S., et al. (2015). Design of salmon calcitonin particles for nasal delivery using spray-drying and novel supercritical fluid-assisted spray-drying processes. Int. J. Pharm. 478, 288-296. doi: 10.1016/j.ijpharm.2014.11.051

Dai, Q., Zhu, X., Abbas, S., Karangwa, E., Zhang, X., Xia, S., et al. (2015). Stable nanoparticles prepared by heating electrostatic complexes of whey protein isolate-dextran conjugate and chondroitin sulfate. J. Agric. Food Chem. 63, 4179-4189. doi: 10.1021/acs.jafc.5b00794

Dalgleish, D. G. (2006). Food emulsions - their structures and structure-forming properties. Food Hydrocoll. 20, 415-422. doi: 10.1016/j.foodhyd.2005.10.009

Davidov-Pardo, G., Joye, I. J., Espinal-Ruiz, M., and McClements, D. J. (2015a). Effect of maillard conjugates on the physical stability of zein nanoparticles prepared by liquid antisolvent coprecipitation. J. Agric. Food Chem. 63, 8510-8518. doi: 10.1021/acs.jafc.5b02699

Davidov-Pardo, G., Joye, I. J., and McClements, D. J. (2015b). Food-grade proteinbased nanoparticles and microparticles for bioactive delivery: fabrication, 
characterization, and utilization. Adv. Protein Chem. Struct. Biol. 98, 293-325. doi: 10.1016/bs.apcsb.2014.11.004

Dominguez-Medina, S., Kisley, L., Tauzin, L. J., Hoggard, A., Shuang, B. D. S., Indrasekara, A. S., et al. (2016). Adsorption and unfolding of a single protein triggers nanoparticle aggregation. ACS Nano 10, 2103-2112. doi: 10.1021/acsnano.5b06439

Ercili-Cura, D., Partanen, R., Husband, F., Ridout, M., Macierzanka, A., Lille, M., et al. (2012). Enzymatic cross-linking of $\beta$-lactoglobulin in solution and at air-water interface: structural constraints. Food Hydrocoll. 28, 1-9. doi: 10.1016/j.foodhyd.2011.11.010

Fernández-Ávila, C., Escriu, R., and Trujillo, A. J. (2015). Ultra-high pressure homogenization enhances physicochemical properties of soy protein isolate-stabilized emulsions. Food Res. Int. 75, 357-366. doi: 10.1016/j.foodres.2015.05.026

Fu, J., and Schlenoff, J. B. (2016). Driving forces for oppositely charged polyion association in aqueous solutions: enthalpic, entropic, but not electrostatic. J. Am. Chem. Soc. 138, 980-990. doi: 10.1021/jacs.5b11878

Gomez, A., Bingham, D., Juan, L. D., and Tang, K. (1998). Production of protein nanoparticles by electrospray drying. J. Aerosol Sci. 29, 561-574. doi: 10.1016/S0021-8502(97)10031-3

Gossmann, R., Fahrländer, E., Hummel, M., Mulac, D., Brockmeyer, J., and Langer, K. (2015). Comparative examination of adsorption of serum proteins on HSAand PLGA-based nanoparticles using SDS-PAGE and LC-MS. Eur. J. Pharm. Biopharm. 93, 80-87. doi: 10.1016/j.ejpb.2015.03.021

Gülseren, I., Güzey, D., Bruce, B. D., and Weiss, J. (2007). Structural and functional changes in ultrasonicated bovine serum albumin solutions. Ultrason. Sonochem. 14, 173-183. doi: 10.1016/j.ultsonch.2005.07.006

Hu, H., Wu, J., Li-Chan, E. C. Y., Zhu, L., Zhang, F., Xu, X., et al. (2013). Effects of ultrasound on structural and physical properties of soy protein isolate (SPI) dispersions. Food Hydrocoll. 30, 647-655. doi: 10.1016/j.foodhyd.2012.08.001

Jaworek, A. (2007). Micro- and nanoparticle production by electrospraying. Powder Technol. 176, 18-35. doi: 10.1016/j.powtec.2007.01.035

Jiang, S.-J., and Zhao, X.-H. (2010). Transglutaminase-induced cross-linking and glucosamine conjugation in soybean protein isolates and its impacts on some functional properties of the products. Eur. Food Res. Technol. 231, 679-689. doi: 10.1007/s00217-010-1319-2

Joye, I. J., Nelis, V. A., and McClements, D. J. (2015). Gliadin-based nanoparticles: fabrication and stability of food-grade colloidal delivery systems. Food Hydrocoll. 44, 86-93. doi: 10.1016/j.foodhyd.2014.09.008

Kamogawa, K., Okudaira, G., Matsumoto, M., Sakai, T., Sakai, H., and Abe, M. (2004). Preparation of oleic acid/water emulsions in surfactant-free condition by sequential processing using midsonic-megasonic waves. Langmuir 20, 2043-2047. doi: 10.1021/la030160z

Karthikeyan, K., Krishnaswamy, V. R., Lakra, R., Kiran, M. S., and Korrapati, P. S. (2015). Fabrication of electrospun zein nanofibers for the sustained delivery of siRNA. J. Mater. Sci. Mater. Med. 26, 101. doi: 10.1007/s10856-0155439-x

Keerati-U-Rai, M., and Corredig, M. (2009). Effect of dynamic high pressure homogenization on the aggregation state of soy protein. J. Agric. Food Chem. 57, 3556-3562. doi: 10.1021/jf803562q

Klemmer, K. J., Waldner, L., Stone, A., Low, N. H., and Nickerson, M. T. (2012). Complex coacervation of pea protein isolate and alginate polysaccharides. Food Chem. 130, 710-715. doi: 10.1016/j.foodchem.2011.07.114

Li, Y., Wu, Z., He, W., Qin, C., Yao, J., Zhou, J., et al. (2015). Globular proteincoated Paclitaxel nanosuspensions: interaction mechanism, direct cytosolic delivery, and significant improvement in pharmacokinetics. Mol. Pharm. 12, 1485-1500. doi: 10.1021/mp5008037

Liu, Y. Y., Zeng, X. A., Deng, Z., Yu, S. J., and Yamasaki, S. (2011). Effect of pulsed electric field on the secondary structure and thermal properties of soy protein isolate. Eur. Food Res. Technol. 233, 841-850. doi: 10.1007/s00217-011$1580-\mathrm{Z}$

Liu, Z., and Chen, X. (2016). Simple bioconjugate chemistry serves great clinical advances: albumin as a versatile platform for diagnosis and precision therapy. Chem. Soc. Rev. 45, 1432-1456. doi: 10.1039/C5CS00158G

Loureiro, A., Nogueira, E., Azoia, N. G., Sárria, M. P., Abreu, A. S., Shimanovich, U., et al. (2015). Size controlled protein nanoemulsions for active targeting of folate receptor positive cells. Colloids Surf. B. Biointerfaces 135, 90-98. doi: 10.1016/j.colsurfb.2015.06.073
Lundqvist, M., Sethson, I., and Jonsson, B.-H. (2004). Protein adsorption onto silica nanoparticles: conformational changes depend on the particles' curvature and the protein stability. Langmuir 20, 10639-10647. doi: 10.1021/la0484725

Maltais, A., Remondetto, G. E., and Subirade, M. (2008). Mechanisms involved in the formation and structure of soya protein cold-set gels: a molecular and supramolecular investigation. Food Hydrocoll. 22, 550-559. doi: 10.1016/j.foodhyd.2007.01.026

Moomand, K., and Lim, L.-T. (2014). Properties of encapsulated fish oil in electrospun zein fibres under simulated in vitro conditions. Food Bioprocess Technol. 8, 431-444. doi: 10.1007/s11947-014-1414-7

Obermeyer, A. C., Mills, C. E., Dong, X.-H., Flores, R. J., and Olsen, B. D. (2016). Complex coacervation of supercharged proteins with polyelectrolytes. Soft Matter 12, 3570-3581. doi: 10.1039/C6SM00002A

Oh, N., and Park, J.-H. (2014). Endocytosis and exocytosis of nanoparticles in mammalian cells. Int. J. Nanomedicine 9(Suppl. 1), 51-63. doi: 10.2147/IJN.S26592

Partanen, R., Forssell, P., Mackie, A., and Blomberg, E. (2013). Interfacial crosslinking of $\beta$-casein changes the structure of the adsorbed layer. Food Hydrocoll. 32, 271-277. doi: 10.1016/j.foodhyd.2013.01.009

Penalva, R., Esparza, I., Larraneta, E., González-Navarro, C. J., Gamazo, C., and Irache, J. M. (2015). Zein-based nanoparticles improve the oral bioavailability of resveratrol and its anti-inflammatory effects in a mouse model of endotoxic shock. J. Agric. Food Chem. 63, 5603-5611. doi: 10.1021/jf505694e

Pereira, R. N., Rodrigues, R. M., Ramos, Ó. L., Xavier Malcata, F., Teixeira, J. A., and Vicente, A. A. (2015). Production of whey protein-based aggregates under ohmic heating. Food Bioprocess Technol. 9, 576-587. doi: 10.1007/s11947-0151651-4

Perez, A. A., Andermatten, R. B., Rubiolo, A. C., and Santiago, L. G. (2014). $\beta$-Lactoglobulin heat-induced aggregates as carriers of polyunsaturated fatty acids. Food Chem. 158, 66-72. doi: 10.1016/j.foodchem.2014.02.073

Phoon, P. Y., San Martin-Gonzalez, M. F., and Narsimhan, G. (2014). Effect of hydrolysis of soy $\beta$-conglycinin on the oxidative stability of $\mathrm{O} / \mathrm{W}$ emulsions. Food Hydrocoll. 35, 429-443. doi: 10.1016/j.foodhyd.2013.06.024

Priftis, D., Laugel, N., and Tirrell, M. (2012). Thermodynamic characterization of polypeptide complex coacervation. Langmuir 28, 15947-15957. doi: 10.1021/la302729r

Rath, G., Hussain, T., Chauhan, G., Garg, T., and Goyal, A. K. (2016). Collagen nanofiber containing silver nanoparticles for improved wound-healing applications. J. Drug Target. 24, 520-529. doi: 10.3109/1061186X.2015.1095922

Rath, G., Hussain, T., Chauhan, G., Garg, T., and Kumar Goyal, A. (2015). Fabrication and characterization of cefazolin-loaded nanofibrous mats for the recovery of post-surgical wound. Artif. Cells Nanomed. Biotechnol. doi: 10.3109/21691401.2015.1102741. [Epub ahead of print].

Reddy, S. R., and Fogler, H. S. (1980). Emulsion stability of acoustically formed emulsions. J. Phys. Chem. 84, 1570-1575. doi: 10.1021/j100449a027

Relkin, P., Shukat, R., and Moulin, G. (2014). Encapsulation of labile compounds in heat- and high-pressure treated protein and lipid nanoparticles. Food Res. Int. 63, 9-15. doi: 10.1016/j.foodres.2014.03.038

Rodrigues, R. M., Martins, A. J., Ramos, O. L., Malcata, F. X., Teixeira, J. A., Vicente, A. A., et al. (2015). Influence of moderate electric fields on gelation of whey protein isolate. Food Hydrocoll. 43, 329-339. doi: 10.1016/j.foodhyd.2014.06.002

Santiago, L. G., Maldonado-Valderrama, J., Martín-Molina, A., Haro-Pérez, C., García-Martínez, J., Martín-Rodríguez, A., et al. (2008). Adsorption of soy protein isolate at air-water and oil-water interfaces. Colloids Surf. A Physicochem. Eng. Asp. 323, 155-162. doi: 10.1016/j.colsurfa.2007.11.001

Silva, E. K., and Meireles, M. A. A. (2014). Encapsulation of food compounds using supercritical technologies: applications of supercritical carbon dioxide as an antisolvent. Food Public Health. 4, 247-258. doi: 10.5923/j.fph.20140405.06

Sponton, O. E., Perez, A. A., Carrara, C. R., and Santiago, L. G. (2015). Impact of environment conditions on physicochemical characteristics of ovalbumin heatinduced nanoparticles and on their ability to bind PUFAs. Food Hydrocoll. 48, 165-173. doi: 10.1016/j.foodhyd.2015.02.011

Sun, C., Yang, J., Liu, F., Yang, W., Yuan, F., and Gao, Y. (2015). Effects of dynamic high-pressure microfluidization treatment and the presence of quercetagetin on the physical, structural, thermal, and morphological characteristics of zein nanoparticles. Food Bioprocess Technol. 9, 320-330. doi: 10.1007/s11947-015$1627-4$ 
Sun, X. D., and Arntfield, S. D. (2012). Molecular forces involved in heatinduced pea protein gelation: effects of various reagents on the rheological properties of salt-extracted pea protein gels. Food Hydrocoll. 28, 325-332. doi: 10.1016/j.foodhyd.2011.12.014

Teng, Z., Li, Y., Luo, Y., Zhang, B., and Wang, Q. (2013). Cationic $\beta$-lactoglobulin nanoparticles as a bioavailability enhancer: protein characterization and particle formation. Biomacromolecules 14, 2848-2856. doi: 10.1021/bm4006886

Teng, Z., Luo, Y., Li, Y., and Wang, Q. (2016). Cationic beta-lactoglobulin nanoparticles as a bioavailability enhancer: effect of surface properties and size on the transport and delivery in vitro. Food Chem. 204, 391-399. doi: 10.1016/j.foodchem.2016.02.139

Thiering, R., Dehghani, F., Dillow, A., and Foster, N. R. (2000). The influence of operating conditions on the dense gas precipitation of model proteins. J. Chem. Technol. Biotechnol. 75, 29-41. doi: 10.1002/(SICI)10974660(200001)75:1<29::AID-JCTB172>3.0.CO;2-E

Thorat, A. A., and Dalvi, S. V. (2012). Liquid antisolvent precipitation and stabilization of nanoparticles of poorly water soluble drugs in aqueous suspensions: recent developments and future perspective. Chem. Eng. J. 181, 1-34. doi: 10.1016/j.cej.2011.12.044

Tribst, A. A. L., Augusto, P. E. D., and Cristianini, M. (2012). The effect of high pressure homogenization on the activity of a commercial $\beta$-galactosidase. J. Ind. Microbiol. Biotechnol. 39, 1587-1596. doi: 10.1007/s10295-012-1179-9

Tribst, A. A. L., Augusto, P. E. D., and Cristianini, M. (2013). Multipass high pressure homogenization of commercial enzymes: effect on the activities of glucose oxidase, neutral protease and amyloglucosidase at different temperatures. Innov. Food Sci. Emerg. Technol. 18, 83-88. doi: 10.1016/j.ifset.2013.01.002

Walkey, C. D., Olsen, J. B., Guo, H., Emili, A., and Chan, W. C. W. (2012). Nanoparticle size and surface chemistry determine serum protein adsorption and macrophage uptake. J. Am. Chem. Soc. 134, 2139-2147. doi: $10.1021 /$ ja2084338

Wang, Q., Guan, Y.-X., Yao, S.-J., and Zhu, Z.-Q. (2011). Controllable preparation and formation mechanism of BSA microparticles using supercritical assisted atomization with an enhanced mixer. J. Supercrit. Fluids 56, 97-104. doi: 10.1016/j.supflu.2010.12.002

Wang, Y.-H., Wan, Z.-L., Yang, X.-Q., Wang, J.-M., Guo, J., and Lin, Y. (2016). Colloidal complexation of zein hydrolysate with tannic acid: constructing peptides-based nanoemulsions for alga oil delivery. Food Hydrocoll. 54, 40-48. doi: 10.1016/j.foodhyd.2015.09.020

Weber, C., Coester, C., Kreuter, J., and Langer, K. (2000). Desolvation process and surface characterisation of protein nanoparticles. Int. J. Pharm. 194, 91-102. doi: 10.1016/S0378-5173(99)00370-1

Weiss, J., Kanjanapongkul, K., Wongsasulak, S., and Yoovidhya, T. (2012). "Electrospun fibers: fabrication, functionalities and potential food industry applications," in Nanotechnology in the Food, Beverage and Nutraceutical Industries, ed Q. Huang (Cambridge, UK: Woodhead Publishing Limited), 362-397.

Weissler, A. (1959). Formation of hydrogen peroxide by ultrasonic waves: free radicals. J. Am. Chem. Soc. 81, 1077-1081. doi: 10.1021/ja01514a015
Xu, F., Reiser, M., Yu, X., Gummuluru, S., Wetzler, L., and Reinhard, B. M. (2016). Lipid-mediated targeting with membrane-wrapped nanoparticles in the presence of corona formation. ACS Nano 10, 1189-1200. doi: 10.1021/acsnano.5b06501

Yallapu, M. M., Chauhan, N., Othman, S. F., Khalilzad-Sharghi, V., Ebeling, M. C., Khan, S., et al. (2015). Implications of protein corona on physico-chemical and biological properties of magnetic nanoparticles. Biomaterials 46, 1-12. doi: 10.1016/j.biomaterials.2014.12.045

Yao, X.-T., and Zhao, X.-H. (2016). Pre-deamidation of soy protein isolate exerts impacts on transglutaminase-induced glucosamine glycation and cross-linking as well as properties of the products. J. Sci. Food Agric. 96, 2418-2425. doi: $10.1002 /$ jsfa.7361

Ye, L., Liao, Y., Zhao, M., and Sun, W. (2013). Effect of protein oxidation on the conformational properties of peanut protein isolate. J. Chem. 2013:423254. doi: $10.1155 / 2013 / 423254$

Yu, Z.-L., Zeng, W.-C., Zhang, W.-H., Liao, X.-P., and Shi, B. (2016). Effect of ultrasonic pretreatment on kinetics of gelatin hydrolysis by collagenase and its mechanism. Ultrason. Sonochem. 29, 495-501. doi: 10.1016/j.ultsonch.2015.11.004

Zeeb, B., Salminen, H., Fischer, L., and Weiss, J. (2013). Impact of heat and laccase on the $\mathrm{pH}$ and freeze-thaw stability of oil-in-water emulsions stabilized by adsorbed biopolymer nanoparticles. Food Biophys. 9, 125-137. doi: 10.1007/s11483-013-9325-0

Zhai, J. L., Day, L., Aguilar, M.-I., and Wooster, T. J. (2013). Protein folding at emulsion oil/water interfaces. Curr. Opin. Colloid Interface Sci. 18, 257-271. doi: 10.1016/j.cocis.2013.03.002

Zhang, J., Liang, L., Tian, Z., Chen, L., and Subirade, M. (2012). Preparation and in vitro evaluation of calcium-induced soy protein isolate nanoparticles and their formation mechanism study. Food Chem. 133, 390-399. doi: 10.1016/j.foodchem.2012.01.049

Zhang, Q.-T., Tu, Z.-C., Xiao, H., Wang, H., Huang, X.-Q., Liu, G.-X., et al. (2014). Influence of ultrasonic treatment on the structure and emulsifying properties of peanut protein isolate. Food Bioprod. Process. 92, 30-37. doi: 10.1016/j.fbp.2013.07.006

Zhao, J., Dong, F., Li, Y., Kong, B., and Liu, Q. (2015). Effect of freeze-thaw cycles on the emulsion activity and structural characteristics of soy protein isolate. Process Biochem. 50, 1607-1613. doi: 10.1016/j.procbio.2015.06.021

Conflict of Interest Statement: The authors declare that the research was conducted in the absence of any commercial or financial relationships that could be construed as a potential conflict of interest.

Copyright (c) 2016 Rajendran, Udenigwe and Yada. This is an open-access article distributed under the terms of the Creative Commons Attribution License (CC $B Y)$. The use, distribution or reproduction in other forums is permitted, provided the original author(s) or licensor are credited and that the original publication in this journal is cited, in accordance with accepted academic practice. No use, distribution or reproduction is permitted which does not comply with these terms. 